\title{
The matrix revisited
}

\author{
Jonathan D'Cunha, MD, PhD
}

From the Department of Cardiothoracic Surgery, University of Pittsburgh Medical Center, Pittsburgh, Pa.

Disclosures: Author has nothing to disclose with regard to commercial support.

Received for publication Dec 17, 2017; accepted for publication Dec 23, 2017; available ahead of print Feb 2, 2018.

Address for reprints: Jonathan D'Cunha, MD, PhD, Department of Cardiothoracic Surgery, University of Pittsburgh Medical Center, UPMC Presbyterian, Suite C-900, 200 Lothrop St, Pittsburgh, PA 15213 (E-mail: dcunhaj@upmc.edu).

J Thorac Cardiovasc Surg 2018;155:2176

$0022-5223 / \$ 36.00$

Copyright (C) 2018 by The American Association for Thoracic Surgery

https://doi.org/10.1016/j.jtcvs.2017.12.111

Non-small cell lung cancer (NSCLC) remains a major US and international health problem with significantly limited stage-specific survival. Even in patients with early-stage NSCLC who undergo surgical resection, 5-year survival is limited. Although there are many factors that have the potential to contribute to this, in recent years many have advocated that the primary tumors themselves have varying aggressiveness. ${ }^{2}$ This is reflected in results that invasion and metastasis remain the main cause of recurrence and death in NSCLC.

Metastasis is the final stage in tumor progression. In the progression of a tumor, one of the critical steps involves degradation of different components of the extracellular matrix and requires the action of proteolytic enzymes such as serine-, cysteinyl-, and aspartyl-proteinases, as well as matrix metalloproteinases (MMPs). The MMP family comprises 24 zinc-dependent endopeptidases with various enzymatic activities that are aimed at breaking down the extracellular matrix. In normal development, controlled regulation of MMP activity is associated with critical physiologic processes, including ovulation, trophoblast invasion, mammary involution, and embryonic development. Numerous studies have demonstrated that this degradation is a critical step in tumor metastasis. This mechanistic process is also present in other pathologies, such as emphysema, rheumatoid arthritis, multiple sclerosis, aortic aneurysms, arterial restenosis lesions, and bullous skin disorders. ${ }^{3}$

Although many MMPs have had their function in tumorigenesis and metastasis characterized and investigated, the role of MMP-12 in the pathogenesis of NSCLC remains largely unknown. MMP-12 is also known as "macrophage elastase" and cleaves elastin after being produced by activated macrophages in premalignant lung diseases. The overexpression of MMP-12 promotes excessive degradation of elastin thereby resulting in parenchymal damage. MMP-12 is highly expressed in NSCLC, and because of its preferential expression being limited to tumor cells, it has the potential to be an attractive therapeutic target. ${ }^{4}$

The actual role of MMP-12 in NSCLC is largely unknown. Previous work has yielded conflicting findings,

which sets the basis for the work reported by Ella and colleagues $^{5}$ in this issue of the Journal. In their work, the authors have comprehensively demonstrated that tumor cells from a diverse set of human NSCLC expressed MMP-12, and this correlated with reduced survival. Interestingly, the expression of MMP-12 was found mainly in tumor cells and not in tumor-infiltrating cells. Further, the authors went on to demonstrate in laboratory studies both in vitro and in vivo that MMP-12 absence resulted in reduced tumor growth and invasiveness. These in vivo experiments are particularly compelling because they were performed in MMP-12 knockout mice.

The power of the study presented by Ella and colleagues ${ }^{5}$ is the story that has been put forth in terms of unifying the understanding of a particular protein and its role in a critical step in the tumorigenesis in NSCLC. Further studies are warranted to demonstrate if in fact MMP-12 may be a viable therapeutic target that helps prevent the progression of NSCLC and thereby positively affecting this worldwide health problem.

\section{References}

1. Nar H, Werle K, Bauer MM, Dollinger H, Jung B. Crystal structure of human macrophage elastase (MMP-12) in complex with a hydroxamic acid inhibitor. $J$ Mol Biol. 2001;312:743-51.

2. Rotow J, Bivona TG. Understanding and targeting resistance mechanisms in NSCLC. Nat Rev Cancer. 2017;17:637-58.

3. Zucker S, Cao J, Chen WT. Critical appraisal of the use of matrix metalloproteinase inhibitors in cancer treatment. Oncogene. 2000;19:6642-50.

4. Hofmann HS, Hansen G, Richter G, Taege C, Simm A, Silber RE, et al. Matrix metalloproteinase-12 expression correlates with local recurrence and metastatic disease in non-small cell lung cancer patients. Clin Cancer Res. 2005;11:1086-92.

5. Ella E, Harel Y, Abraham M, Wald H, Benny O, Karsch-Bluman A, et al. Matrix metalloproteinase 12 promotes tumor propagation in the lung. J Thorac Cardiovasc Surg. 2018;155:2164-75.e1. 